\title{
"DEVES SUBMETER-SE NÃO IMPORTA A QUÊ" - O IMPERATIVO CATEGÓRICO DA INDÚSTRIA CULTURAL E OS CONCEITOS DE VALOR E ESCLARECIMENTO EM KANT
}

\author{
"You must submit no matter what" - The categorical imperative of the culture industry \\ and the concepts of value and enlightenment in Kant
}

Kelly Janaína Souza da Silva*

\begin{abstract}
Resumo: Este trabalho tem como objetivo abordar os conceitos de valor, esclarecimento e imperativo categórico na concepção do filósofo Immanuel Kant e confrontá-los com o que Adorno e Horkheimer chamam de "imperativo categórico da indústria cultural": a apropriação do indivíduo como um meio para que sejam atingidos os objetivos da cultura mercantilizada. Adorno afirma que o sujeito consumidor é objeto dessa indústria e, para ela, o homem é substituível e tido como mero instrumento de trabalho e consumo. Porém, incapaz de perceber que é manipulado, ele se faz crer soberano e autônomo. Para tanto, além de apresentar uma breve introdução ao conceito de valor kantiano como algo que possui valor em si mesmo, faz-se a leitura do opúsculo Resposta à pergunta: que é esclarecimento?, de 1783, com a finalidade de compreender de que modo, em Kant, se dá a passagem do homem "menor" ao seu estado de maioridade e de como a indústria cultural, investida em seu poder de influência, pode fazer o papel oposto, tratando de manter o homem em sua menoridade e satisfazer interesses próprios com isso. Por fim, apresentar argumentos que demonstram como a indústria cultural trabalha para que o mundo seja como ela sugere, evitando a formação de indivíduos independentes, autônomos, capazes de julgar e decidir conscientemente.
\end{abstract}

Palavras-chave: Indústria Cultural. Esclarecimento. Imperativo Categórico.

\begin{abstract}
This work has a objective to approach the concepts of value, enlightenment and categorical imperative in the conception of philosopher Immanuel Kant and confront them with what Adorno and Horkheimer call "categorical imperative of cultural industry": the appropriation of the individual as a agent for them to be achieved the objectives of commercial culture. Adorno claims that the consumer subject is object of this industry and, for its, the man is replaceable and taken as a mere instrument of labor and consumption. However, unable to realize that it's handled, the man believes sovereign and autonomous. To this end, in addition to presenting a brief introduction to the concept of Kantian value as something that has value in itself, it is reading the pamphlet An Answer to the question: what is enlightenment?, 1783 , in order to understand how in Kant, is the passage from "immature" to their state of adulthood and how the cultural industry, invested in its power to influence man can do the opposite role, trying to keep the man in his immaturity and meet their own interests with it. Finally, we present arguments that demonstrate how the cultural industry works to the world to be as it suggests, preventing the formation of people independent, autonomous, able to judge and decide consciously.
\end{abstract}

Keywords: Cultural Industry. Enlightenment. Categorical Imperative.

\footnotetext{
* Mestranda do Programa de Pós-Graduação em Filosofia da Universidade de Caxias do Sul (UCS). Bolsista da capes. Contato: kelly_phoenix@ hotmail.com
}

\begin{tabular}{|c|c|l|l|l|l|}
\hline intuitio & $\begin{array}{c}\text { ISSN } \\
1983-4012\end{array}$ & Porto Alegre & Vol.7- $\mathrm{N}^{\circ} .1$ & $\begin{array}{c}\text { Junho } \\
2014\end{array}$ & p.192-199 \\
\hline
\end{tabular}


"Deves submeter-se não importa a quê" - O imperativo categórico da indústria cultural e os conceitos de valor e esclarecimento em Kant

Na ética kantiana, destacam-se diversas formulações da "lei moral" ou do "imperativo categórico", mas a afirmação de Kant de que é preciso considerar os seres humanos enquanto "seres de razão", como fins em si mesmos e nunca como meios para qualquer outra coisa, vem como uma das principais máximas a serem tomadas por lei universal.

$\mathrm{Na}$ Idade Moderna, a consideração do valor do ser como fim em si mesmo tornou-se algo muito mais candente, pois os ideais de liberdade humana foram postos com tal clareza e potencial de universalização como jamais visto antes. O Renascimento, a Reforma Protestante, a consequente Contra-Reforma católica e a Revolução mecanicista do século XVII são acontecimentos que pressupõem o ser humano como sujeito da realização de valores estéticos, ético-religiosos e científicos, o que requer autonomia e pertença a um processo emancipatório com relação a tudo que o aprisiona e oprime.

Entretanto, mesmo com essas ideias se exprimindo através de inúmeros pensadores iluministas, em Immanuel Kant a relação entre valor ético e autonomia é a mais clara e coesa, delimitando os três âmbitos em que se desdobra a existência humana: econômico-instrumental, no qual as coisas adquirem um "preço de mercado"; estético, onde o valor é apenas de caráter afetivo; e o propriamente moral, no qual nada tem preço, e destaca-se que aquilo que satisfaz a condição sob a qual algo pode ser considerado um fim em si mesmo não tem apenas um preço (valor relativo), mas uma dignidade (valor interno).

Em seu artigo "O que é esclarecimento?”, Immanuel Kant conceitua como sendo a menoridade a incapacidade de fazer uso do seu entendimento sem a direção de outro indivíduo. Na menoridade, o homem não faz uso de sua razão, mas vive em um estado de heteronomia, que vem a ser quando os outros pensam por ele e as regras impostas são obedecidas sem questionamento. Já na maioridade o homem é capaz de pensar por si mesmo, sendo livre e pleno para fazer uso da própria razão e estabelecer suas próprias leis morais e éticas. Na maioridade, o homem age por dever, é responsável por seus atos e passa da heteronomia a um estado de autonomia, onde é seu auto-legislador. Para que chegue a esse estado autônomo, o homem precisa conquistar o esclarecimento [Aufklärung], que vem a ser o processo de emancipação intelectual que supera a ignorância e a preguiça de pensar por si próprio, além do desenvolvimento da crítica àquilo que é inculcado intelectualmente pelos demais (sejam outros homens, instituições ou governos). Para Kant, é a preguiça em assumir-se e buscar a própria condição esclarecida que impede a humanidade de alçar-se à própria razão, ou seja, alcançar um Estado de seres independentes, responsáveis e lúcidos. Colocam Silva e Bittencourt (2011):

Kant nos proporciona a possibilidade de entender a Aufklärung, enquanto uma infância associada à imaturidade humana, a sua incapacidade aos termos da civilização ou da própria condição do homem. É a incapacidade do homem de servir-se do seu próprio entendimento e por isso depende de outrem (SILVA, BITTENCOURT, 2011, p. 3226).

\begin{tabular}{|c|c|l|l|l|l|}
\hline intuitio & $\begin{array}{c}\text { ISSN } \\
1983-4012\end{array}$ & Porto Alegre & Vol.7 $-\mathrm{N}^{\circ} .1$ & $\begin{array}{c}\text { Junho } \\
2014\end{array}$ & p.192-199 \\
\hline
\end{tabular}


"Deves submeter-se não importa a quê" - O imperativo categórico da indústria cultural e os conceitos de valor e esclarecimento em Kant

O homem é o principal culpado dessa menoridade, quando nele não se encontra a falta de entendimento, mas de decisão e coragem para pensar por si próprio, sem influências externas. No mesmo artigo, Kant também questiona aquelas autoridades que mantêm seus sujeitos em menoridade quando já teriam condições intelectuais de não sê-lo - tais as religiões, formas de governo e, na presente discussão, podemos citar a mídia.

Para reflexão do âmbito midiático, trazemos os pensadores alemães Theodor Adorno e Max Horkheimer. Sua obra Dialética do Esclarecimento (1985) inicia-se com a apresentação do conceito de esclarecimento, que segue por duas linhas: o mito como uma primeira forma de esclarecimento (por ter sido uma tentativa de explicação racional para o mundo) e o esclarecimento que decorre de uma tradição científica. Nesse trabalho, apenas o segundo será considerado. Para os pensadores da Escola de Frankfurt, "o esclarecimento tem perseguido sempre o objetivo de livrar os homens do medo e de investi-los na posição de senhores" (1985, p. 17), o que dialoga diretamente com a posição kantiana da conquista da autonomia pelo sujeito esclarecido. A partir do momento que o homem adquire conhecimento, investe-se de poder e é capaz de discernir e exercer domínio. Nesse sentido, o homem esclarecido pode não se deixar influenciar pelos ditames externos, aos quais se incluem as condutas dirigidas pela indústria cultural.

A indústria cultural é a concentração dos meios de comunicação nas mãos de poucos grupos e tem a característica fundamental de gerar cultura de massas. A cultura massificada trata-se de um produto cultural facilmente assimilável, nivelado por baixo e também descartável, representado essencialmente pela grande imprensa e indústrias cinematográfica e musical, que constituem os pontos mais visíveis dessa ordem cultural. A despeito de sua postura aparentemente democrática e liberal, a cultura massificada realiza impiedosamente os ditames de um sistema de dominação econômica que necessita, entretanto, de uma concordância, pelo menos tácita, das pessoas, para a legitimação de sua existência. Adorno e Horkheimer (1985) a definem como "falsa identidade do universal e do particular": ela traduz a aparência de que o indivíduo e o todo se encontram reconciliados quando, na verdade, tal sistema é um poderoso instrumento para, simultaneamente, gerar lucros e exercer um tipo de controle social. Para todos algo está previsto.

As distinções enfáticas que se fazem entre os filmes das categorias A e B, ou entre as histórias publicadas em revistas de diferentes preços têm menos a ver com seu conteúdo do que com sua utilidade para a classificação, organização e computação estatística dos consumidores. [...] Cada qual deve se comportar, como que espontaneamente, em conformidade com o seu level, previamente caracterizado por certos sinais, e escolher a categoria dos produtos de massa fabricada para seu tipo (ADORNO/ HORKHEIMER, 1985, p. 116).

\begin{tabular}{|c|c|l|l|l|l|}
\hline intuitio & $\begin{array}{c}\text { ISSN } \\
1983-4012\end{array}$ & Porto Alegre & Vol.7- $\mathrm{N}^{\mathrm{o}} .1$ & $\begin{array}{c}\text { Junho } \\
2014\end{array}$ & p.192-199 \\
\hline
\end{tabular}


"Deves submeter-se não importa a quê" - O imperativo categórico da indústria cultural e os conceitos de valor e esclarecimento em Kant

A multiplicação dos meios de comunicação, acessibilidade, recursos e a facilidade para a obtenção de fatores (bens de consumo, acesso à informação, educação, lazer etc), que, no passado, conquistava-se com muito labor para a grande maioria da população, fazem com que esta pareça ser a verdadeira época do acesso, do conhecimento, da liberdade de expressão, pois a informação e a cultura estão por toda a parte e pode-se chegar a elas de diversas formas. Como diz Bauman (2001), o acesso à informação (em sua maioria eletrônica) tornou-se "o direito humano mais zelosamente defendido" (p. 178). Tais ocorrências fazem crer que o pensamento condição essencial para a subjetividade - não é reprimido na sociedade atual, ainda que, muitas vezes, o raciocínio torne-se simplesmente desnecessário.

Entretanto, indivíduos capazes de formular juízos morais e intelectuais além do senso comum, avaliando-os com competência e ciência dos pressupostos, princípios e critérios que estão usando em sua reflexão, não são propriamente desejados. Torna-se a indústria cultural uma auxiliar no processo de manter os indivíduos menores, pois existe uma fonte de opressão na própria sociedade. Socialmente, o funcionamento alienado contribui para a manutenção da própria indústria cultural em moldes manipuladores e regentes dos interesses de poucos, e também para a crescente concentração do capital em cada vez menos mãos, como um modo de controlar o mercado.

No Brasil, os detentores de concessões de grandes canais de televisão são também donos das revistas de maior circulação, além de jornais e estações de rádio. Com isso, há a garantia de que a mesma notícia será veiculada a todas as camadas sociais com a ideologia do veiculante. Por conseguinte, com todos acreditando no que está sendo dito, são aceitos tais modos de vida como naturais, a ordem é mantida e a unidade do sistema permanece coesa, permitindo que os economicamente mais fortes exerçam seu poder sobre a sociedade e difundam a padronização e a produção em série. Na condição de "espectadores", temos a ilusão do acesso aos mais diversos veículos de comunicação, vários canais e mídias, porém, todos iguais uns aos outros (CARMO, 2004). Qualquer vantagem ou desvantagem aparente serve apenas para perpetuar a ilusão de concorrência e possibilidade de escolha. Diz Bauman (2001):

Os espetáculos tomam o lugar da supervisão sem perder o poder disciplinador do antecessor. A obediência aos padrões [...] tende a ser alcançada hoje em dia pela tentação e pela sedução e não mais pela coerção e aparece sob o disfarce do livre-arbítrio, em vez de revelar-se como força externa (BAUMAN, 2001, p. 101).

Almeida (1994) diz que a sociedade, embora não aparente, é uma sociedade oral, e a leitura e a escrita são utilizadas como tendências operativas e funcionais, não tendo como objetivo a criação de pensadores ou a reflexão, mas sim a instrução e o cumprimento de diretrizes preestabelecidas. Ou seja, essa sociedade oral, como defende o autor, precisa de um

\begin{tabular}{|c|c|l|l|l|l|}
\hline intuitio & $\begin{array}{c}\text { ISSN } \\
1983-4012\end{array}$ & Porto Alegre & Vol.7- $\mathrm{N}^{\mathrm{o}} .1$ & $\begin{array}{c}\text { Junho } \\
2014\end{array}$ & p.192-199 \\
\hline
\end{tabular}


"Deves submeter-se não importa a quê" - O imperativo categórico da indústria cultural e os conceitos de valor e esclarecimento em Kant

ouvir incessante e um olhar exterior como sua fonte de informações, valores, conhecimentos, comportamentos a serem imitados. A maioria ouve, vê e fala muito, mas lê pouco, e assim, sons e imagens externos fundem-se na construção mimética da subjetividade do homem urbano, onde permanece imerso em uma eterna "infância da cultura". Postman (2011) corrobora, argumentando que os personagens de ficção vistos regularmente na televisão comercial são mostrados como tendo gostos e linguagem que não sugerem a leitura de livros ou pendam para o devido senso crítico adulto. Diz ele:

Na verdade, é bem evidente que a maioria dos adultos nos shows de TV são mostrados como funcionalmente analfabetos não só no sentido de que o conteúdo da cultura livresca está ausente do que parecem saber, mas também por causa da ausência até mesmo dos mais leves sinais de um hábito contemplativo da mente (POSTMAN, 2011, p. 141).

É muito diferente da imaginação reflexiva, mediada pela palavra escrita e pela sintaxe de um texto literário. É essa homologia com a fala (oral) e com a realidade visível/audível que dá ao cinema e à TV sua força e domínio sobre as populações orais atuais. São os instrumentos e o meio dominante da educação cultural massiva. A aposta é que as massas sejam educadas no dispêndio consumidor, com mentalidades e práticas homogêneas e gostos e atitudes racionalizados. Sendo assim, qualquer competência, perícia e senso crítico podem ser tomados por "arrogância de quem se acha melhor que os outros, quando a cultura distribui tão democraticamente seu privilégio a todos" (ADORNO, 1985, p. 125) e é quando se ratifica a demanda de imundícies e se inaugura a harmonia.

Tanto a indústria cultural quanto os regimes totalitários, em um momento marcado pelo capitalismo monopolista, corporificam suas versões "democrática" e ditatorial. Essa "democracia" atribuída à indústria cultural não significa que ela seja democrática, de fato, no sentido mais pleno do termo; mas que seja democraticamente formal, como tudo no Ocidente: a aparência de liberdade, a necessidade absoluta de manter um ar liberal. Seu dissimulado caráter "antidemocrático", porém, revela-se já no fato de que ela impõe ao público apenas o que lhe interessa, no sentido de valorizar o capital investido e ou manter a ideologia do status quo, sob a aparência de atender-lhe as demandas. Há também uma função ideológica de que a maior proximidade possível de que a indústria cultural seja capaz de ter com seu público garanta uma perscrutação de suas necessidades latentes, adequando a oferta e não permitindo que a manipulação se revele enquanto tal. Essa ilusão de "democracia", combinada com muito mais ignorância é o que estabelece uma espécie de cumplicidade entre a indústria cultural e o público, permitindo que a cultura mercantilizada transmute o esclarecimento em enganação total das massas, sempre no sentido de cumprir os objetivos de lucratividade e manutenção da ordem vigente. Diz Silva (2004):

\begin{tabular}{|c|c|l|l|l|l|}
\hline intuitio & $\begin{array}{c}\text { ISSN } \\
1983-4012\end{array}$ & Porto Alegre & Vol.7 $-\mathrm{N}^{\circ} .1$ & $\begin{array}{c}\text { Junho } \\
2014\end{array}$ & p.192-199 \\
\hline
\end{tabular}


O homem é tão bem manipulado e ideologizado que até mesmo o seu lazer se torna uma extensão do trabalho. Portanto, o homem ganha um coraçãomáquina. Tudo que ele fará, fará segundo o seu coração-máquina, isto é, segundo a ideologia dominante. A Indústria Cultura, que tem como guia a racionalidade técnica esclarecida, prepara as mentes para um esquematismo que é oferecido pela indústria da cultura - que aparece para os seus usuários como um "conselho de quem entende". O consumidor não precisa se dar ao trabalho de pensar, é só escolher. É a lógica do clichê. Esquemas prontos que podem ser empregados indiscriminadamente só tendo como única condição a aplicação ao fim a que se destinam (SILVA, 2004).

A preguiça e a covardia são as principais causas pelas quais os homens permanecem "menores", de bom grado, por toda a vida. Há comodidade em que os outros pensem por eles, em apenas seguir o que é determinado. Estas são também as causas pelas quais é tão fácil com que alguém se lhes solape a autonomia. O próprio Kant afirma que, para o esclarecimento, nada mais é exigido senão a liberdade, uma vez que toda ação exige o uso público ou privado da razão ${ }^{1}$. Entretanto, mesmo manter-se "maior" pode ser complicado em termos de cultura como monopólio privado. Quando a arte é determinada pelo poder de compra, arte e cultura funcionam cada vez mais como um investimento financeiro, cujo retorno deve obedecer à remuneração do capital empregado. Atualmente, o número de produtos culturais como filmes e livros lançados anualmente é exorbitante. Essa multiplicação da oferta de produtos é uma das facetas que tem como função minimizar o risco de insucesso, além de atender à exigência de rentabilidade rápida, pois são alguns dos parâmetros de desempenho do sucesso desses produtos. Isso dificulta e até impede que se cultivem artistas natos, que pensem com mentalidade própria, pois é preciso submeter cada impulso artístico ao juízo de mercado. O que nunca foi experimentado é descartado, por se tratar de um risco, e quem tentar trazer esclarecimento através de sua arte pode ser arrebatadoramente apenado. Dizem Adorno e Hockeimer na trilha de Tocqueville:

[...] a tirania deixa o corpo livre e vai direto à alma. O mestre não diz mais: você pensará como eu ou morrerá. Ele diz: você é livre de não pensar como eu: sua vida, seus bens, tudo você há de conservar, mas de hoje em diante você será um estrangeiro entre nós. Quem não se conforma é punido com uma impotência econômica que se prolonga na impotência espiritual do individualista. Excluído da atividade industrial, ele terá sua insuficiência facilmente comprovada (ADORNO, 1985, p.125).

Trata-se da imanente existência de castração no ar, dirigida a todos que não se dispõem espontaneamente a colaborar com a manutenção do sistema, tendo no próprio sistema de dominação o papel de autoridade impessoal e difusa. A cultura industrializada pode se permitir indignar com o capitalismo, mas não de abdicar da ameaça de castração. $\mathrm{O}$ espectador não deve

\footnotetext{
${ }^{1}$ De acordo com Kant, o uso privado da razão é conceituado como aquele realizado em certo cargo público ou função confiada, e o uso público da razão aquele que qualquer homem faz diante do grande público do mundo letrado.
}

\begin{tabular}{|c|c|l|l|l|l|}
\hline intuitio & $\begin{array}{c}\text { ISSN } \\
1983-4012\end{array}$ & Porto Alegre & Vol.7- $\mathrm{N}^{\circ} .1$ & $\begin{array}{c}\text { Junho } \\
2014\end{array}$ & p.192-199 \\
\hline
\end{tabular}


"Deves submeter-se não importa a quê" - O imperativo categórico da indústria cultural e os conceitos de valor e esclarecimento em Kant

ter necessidade de nenhum pensamento próprio, o produto prescreve toda reação. Dessa forma, se torna decisiva a necessidade intrínseca ao sistema de não soltar o consumidor e não the permitir o pressentimento da possibilidade de resistência, o que também pode significar mantêlo em menoridade.

Aqui, a menoridade do sujeito serve até mesmo de predicado à sua permanência como indivíduo passivo, o "cliente" típico da indústria cultural: alguém com estrutura psíquica frágil e malformada, incapaz de resistir aos apelos da sociedade de consumo e à subserviência do status quo (NOVAES, 2004, p. 106-107). O sucesso e continuidade da indústria cultural pressupõem a existência de indivíduos que não são necessariamente sujeitos, suprimindo a autonomia pressuposta na ação ética e exprimindo tal fato esteticamente em suas mercadorias culturais. Ou seja, a liberdade e a autorreflexão por parte do sujeito são eliminadas. E a indústria cultural ordena tanto a competição desmedida quanto a compra de bugigangas inúteis e todos obedecem.

A mística bem alimentada [...] da satisfação e da escolha individuais, ponto culminante de uma civilização da "liberdade", constitui a própria ideologia do sistema industrial, justificando a arbitrariedade e todos os danos colectivos: lixo, poluição, desculturação - de facto, o consumidor é soberano em plena selva de fealdade em cujo seio se lhe impôs a liberdade de escolha (BAUDRILLARD, 1995, p. 72).

Kant define imperativo por "toda proposição que expressa uma possível ação livre, por meio da qual se concretiza um determinado fim" e diz que, se uma ação representada é boa em $s i$, necessária numa vontade em si conforme à razão como princípio dessa vontade, então o imperativo é categórico. Adorno cunha o termo de Kant para dizer que a indústria cultural tem apenas um imperativo categórico: "Deves submeter-se, não importa a quê". É a submissão da entrega - "menos ao amor do que ao respeito" - por aquilo que a sociedade espera, e também, o indivíduo como meio para os fins pretendidos pela indústria da cultura.

Diante desse quadro, a sobrevivência ética frente aos objetos e produtos da indústria cultural pode depender essencialmente em manter-se esclarecido, ainda que para isso seja indispensável a liberdade - e haja limitação por toda a parte. Adorno defendia que, no fundo, as imagens veiculadas pela indústria cultural são uma forma de escrita ideológica, portadora do papel que a cada um cabe desempenhar na sociedade tardo-capitalista. E o papel que o pensamento dialético pode ter na crítica ao atual estado de coisas pode ser a resposta a um decorrente posicionamento ético, que seja digno do nome e, por consequência, de sujeitos esclarecidos - ou "maiores", de acordo com o opúsculo kantiano.

\begin{tabular}{|c|c|l|l|l|l|}
\hline intuitio & $\begin{array}{c}\text { ISSN } \\
1983-4012\end{array}$ & Porto Alegre & Vol.7- $\mathrm{N}^{\mathrm{o}} .1$ & $\begin{array}{c}\text { Junho } \\
2014\end{array}$ & p.192-199 \\
\hline
\end{tabular}


"Deves submeter-se não importa a quê" - O imperativo categórico da indústria cultural e os conceitos de valor e esclarecimento em Kant

\section{Referências}

ADORNO Theodor W. ; HORKHEIMER Max. Dialética do Esclarecimento. Fragmentos Filosóficos. Rio de Janeiro: Jorge Zahar Editor, 1985.

ALMEIDA, Milton José de. Imagens e Sons: A nova cultura oral. São Paulo: Cortez, 1994.

BAUDRILLARD, Jean. A sociedade de consumo. Lisboa (Portugal): Edições 70, 1995.

BAUMAN, Zygmunt. Modernidade Líquida. Tradução de Plínio Dentzien. Rio de Janeiro: Jorge Zahar, 2001.

DUARTE, Rodrigo. Adorno/ Horkheimer - A dialética do esclarecimento. Filosofia passo-apasso. Rio de Janeiro: Jorge Zahar Editor, 2002.

KANT, Immanuel. Crítica da Razão Pura e outros textos filosóficos. Seleção de Marilena de Souza Chauí Berlinck. São Paulo: Abril Cultural, 1974.

KANT, Immanuel. Resposta à pergunta: Que é esclarecimento? Textos Seletos. Tradução: Floriano de Sousa Fernandes. 3 ed. Rio de Janeiro: Editora Vozes, 2005.

NOVAES, Adauto (org.). Muito além do espetáculo. São Paulo: Senac São Paulo, 2005.

POSTMAN, Neil. O desaparecimento da infância. Rio de Janeiro: Graphia, 2011.

Obras disponíveis online

CARMO, Josué G. B. A indústria cultural ou como a vida imita a arte. 2004. Disponível em: http://www.educacaoliteratura.com.br/index\%20128.htm Acesso em: 24 de março de 2014, 18:13hs.

SILVA, Daniel Ribeiro da. Adorno e a Indústria Cultural. Revista Urutagua, Maringá: PR, Quadrimestral, n. ${ }^{\circ}$ 04, Ano I. Maio de 2002. Disponível em: < http://www.urutagua.uem.br//04fil_silva.htm > Acesso em: 07 de abril de 2014, 14:52 hs.

SILVA, Anilde Tombolato Tavares da; BITTENCOURT, Cândida Alayde de Carvalho. Educação para a emancipação na contemporaneidade: Algumas aproximações entre o pensamento de Kant e Adorno. 2011. Disponível em: http://educere.bruc.com.br/CD2011/pdf/4646_2523.pdf Acesso em: 07 de abril de 2014, 16:15 hs.

Recebido em: 12/04/2014

Aprovado para publicação em: 13/05/2014

\begin{tabular}{|c|c|l|l|l|l|}
\hline intuitio & $\begin{array}{c}\text { ISSN } \\
1983-4012\end{array}$ & Porto Alegre & Vol.7- $\mathrm{N}^{\circ} .1$ & $\begin{array}{c}\text { Junho } \\
2014\end{array}$ & p.192-199 \\
\hline
\end{tabular}

